\title{
Conhecimento e adesão às práticas de biossegurança em um hospital de referência materno infantil
}

\author{
Knowledge and adherence to biosafety practices in a \\ maternal and infant referral hospital \\ Daniela Mara Marinho Pereira', Nathália Rabelo Costa ${ }^{1}$, Marlucy Nunes Andrade', Daniel da Costa Torres ${ }^{1}$, \\ Rodrigo Santiago Barbosa Rocha², Paulo Eduardo Santos Avila ${ }^{1}$
}

RESUMO Objetivo: avaliar o nível de conhecimento e adesão das normas de Biossegurança no setor materno infantil de um hospital de referência. Método: pesquisa de campo exploratória descritiva transversal quali-quantitativa realizada na Fundação Santa Casa de Misericórdia do Pará com 54 funcionários dos setores de enfermaria clínica pediátrica e enfermaria cirúrgica pediátrica. Resultados: os dados foram coletados por meio da aplicação de questionário com perguntas acerca de assuntos gerais de Biossegurança, onde 95\% dos funcionários declararam saber o que é Biossegurança, 59,26\% dos funcionários declararam que já receberam algum treinamento em Biossegurança e 51,58\% desconhece as Normas Regulamentadoras relacionadas a prática em Biossegurança. Conclusão: a pesquisa relatou a percepção dos trabalhadores da FSCMP sobre os conceitos de segurança associados aos serviços de saúde e constatou a necessidade de fortalecer nos trabalhadores os conceitos relacionados a Biossegurança.

Descritores: Biossegurança, exposição ao risco, riscos ocupacionais.

ABSTRACT Purpose: the present study aimed to evaluate the level of knowledge and adherence to Biosafety standards in the maternal and child health sector of a referral hospital. Method: a qualitative and quantitative cross-sectional descriptive exploratory field survey was carried out at the Santa Casa de Misericórdia Foundation of Pará with 54 employees from the pediatric clinical nursing and pediatric surgical ward sectors. Results: the data were collected through the application of a questionnaire with questions about general Biosafety issues, where $95 \%$ of the employees stated that they know what Biosafety is, $59.26 \%$ of the employees stated that they have already received some training in Biosafety and 51.58\% it does not know the Regulatory Norms related to the practice in Biosafety. Conclusion: the research reported the perception of FSCMP workers on the concepts of safety associated with health services and noted the need to strengthen in workers the concepts related to Biosafety.

Keywords: Biosafety, exposure to risk, occupational risks.

'Universidade da Amazônia - UNAMA, Belém, PA, Brasil

${ }^{2}$ Universidade do Estado do Pará - UEPA, Belém, PA, Brasil

Fonte de financiamento: Nenhuma.

Conflito de interesses: Os autores declaram não haver conflitos de interesse.

Recebido: Junho 27, 2018

Aceito: Junho 29, 2018

Trabalho realizado na Fundação Santa Casa de Misericórdia do Pará - FSCMP, Belém, PA Brasil. 


\section{Introdução}

Segundo o Ministério da Saúde a Biossegurança tem papel fundamental na prevenção e promoção da saúde por abranger um conjunto de ações e normas com a finalidade de minimizar ou eliminar os riscos característicos das atividades profissionais que possam vir a comprometer a saúde do indivíduo e o meio ambiente ${ }^{1}$.

Os profissionais de saúde estão diariamente expostos ao risco de acidentes com materiais biológicos e pérfuro cortantes contaminados. Logo, é necessário que haja o entendimento sobre a importância dos cuidados de Biossegurança que preconizam a diminuição desta exposição por meio de medidas de prevenção, principalmente por meio dos equipamentos de proteção individual (EPIs) e do descarte adequado destes materiais ${ }^{2}$.

A Biossegurança dispõe de várias Normas Regulamentadoras (NRs), que para serem efetivas, é indispensável que todos os profissionais envolvidos no ambiente de risco, tenham o devido conhecimento em relação as suas diretrizes e serem capazes de adaptá-las a sua rotina de forma correta ${ }^{3}$.

Em 1978, o Ministério do Trabalho lançou a Norma Regulamentadora $n^{\circ} 32$ (NR 32), que determina as diretrizes básicas referentes a medidas de segurança e proteção à saúde dos profissionais que atuam em ambientes de risco ${ }^{4}$. Como complemento, foi lançada a Norma Regulamentadora $n^{\circ} 9$ (NR 9) que corresponde à obrigatoriedade de identificação dos riscos, delegando às Comissões Internas de Prevenção a Acidentes (CIPA) o planejamento de mapas de riscos ambientais ${ }^{5}$.

A Biossegurança é indispensável ao fortalecimento da aprendizagem durante a formação acadêmica, devendo atingir o nível excelência no conhecimento e adesão às suas normas e cuidados necessários às práticas diárias com a educação continuada nas instituições de saúde ${ }^{6}$.

Os profissionais de saúde estão diariamente expostos ao risco de acidentes com materiais biológicos e pérfuro cortantes contaminados. Logo, é necessário que haja o entendimento sobre a importância dos cuidados de Biossegurança que preconizam a diminuição desta exposição por meio de medidas de prevenção, principalmente por meio dos equipamentos de proteção individual (EPIs) e do descarte adequado destes materiais ${ }^{2}$.

O nível de conhecimento em Biossegurança e suas práticas devem ser suficientes, visto o nível de exposição de seus funcionários, tendo a presente pesquisa o objetivo de avaliar o nível de conhecimento e adesão das normas de Biossegurança no setor materno infantil de um hospital de referência.

\section{Materiais e métodos}

Este estudo se configura na modalidade de pesquisa de campo exploratória descritivo transversal qualitativo e quantitativo realizado na Fundação Santa Casa de Misericórdia do Pará (FSCMP), no período de março a maio de 2017, envolvendo os turnos da manhã, tarde e noite nos setores de enfermaria clínica pediátrica e enfermaria cirúrgica pediátrica.

A coleta de dados foi feita por meio da aplicação de questionário com perguntas acerca de assuntos gerais de Biossegurança, uso de equipamentos de proteção individuais, descarte de materiais, riscos biológicos e químicos, mapas de risco, higienização, normas regulamentadores, acidentes de trabalho, contendo ainda, perguntas subjetivas acerca de práticas laborais diárias.

A amostra foi constituída por 56 funcionários que responderam o questionário, de um total amostral de 93 funcionários lotados nos dois setores acima descritos, nos três turnos, que apresentavam contato direto com pacientes, sendo as categoriais profissionais participantes da pesquisa composta por assistentes sociais, auxiliares de serviços gerais, enfermeiros, fisioterapeutas, fonoaudiólogos, médicos, psicólogos, técnicos de enfermagem e terapeutas ocupacionais, de ambos os gêneros.

Foram excluídos do estudo aqueles que não exercem suas atividades profissionais no setor de pediatria, assim como os que não aceitaram participar voluntariamente mediante a assinatura do Termo de Consentimento Livre e Esclarecido. Este estudo foi conduzido segundo a Resolução 466/12 do Conselho Nacional de Saúde e após aprovação do Comitê de Ética em Pesquisa da FSCMP sob o parecer consubstanciado $\mathrm{n}^{\mathrm{o}} 1.994 .702$. 
Para a análise estatística foi utilizado o teste não paramétrico Qui-quadrado de Pearson para tendência/aderência e para associação entre variáveis nominais, simbolizado por $\chi^{2}$, adotando-se um nível de significância de p-valor $<0,05$. Os dados coletados foram tabulados, interpretados e analisados por meio da estatística descritiva e inferencial, utilizando os sistemas Microsoft Excel, Statistic Package for Social Sciences (SPSS) versão 22.0, todos em ambiente Windows 10.

\section{Resultados}

A amostra foi composta por 54 funcionários dos setores de enfermaria clínica pediátrica e enfermaria cirúrgica pediátrica da FSCMP, na cidade de Belém do Pará. Verifica-se que a taxa de proporção de funcionários participantes da pesquisa é significativa ( $\mathrm{p}<0.05)$, considerando que do total de 93 funcionários disponíveis, 54 (58,06\%) participaram da pesquisa, e esta proporção varia no intervalo de confiança (IC 95\%) entre $47,37 \%$ e $68,22 \%$

A pesquisa buscou saber dos trabalhadores o conhecimento dos mesmos sobre o conceito de Biossegurança bem como sobre as normas de Biossegurança e das normas relacionadas como evidenciado na Tabela 1.

A Tabela 2 demonstra o conhecimento dos funcionários sobre o conceito de Biossegurança.

A Tabela 3 demonstra a percepção dos funcionários quanto ao material biológico ao que mais tem contato durante o trabalho em suas respectivas unidades.

A Tabela 4 fornece um panorama sobre o comportamento dos funcionários com relação as normas de Biossegurança.

A Tabela 5 exibe informações sobre a cultura de Biossegurança dos funcionários do hospital FSCMP e acerca do conhecimento de cada funcionário quanto ao procedimento correto de higienização das mãos bem como sobre o cuidado que o funcionário tem com seu jaleco.

Tabela 1: Distribuição de funcionários participantes da pesquisa, segundo o conhecimento do conceito de Biossegurança e as normas relacionadas às práticas, FSCMP, Belém-PA, 2017

\begin{tabular}{|c|c|c|c|}
\hline Questões & $\mathbf{n}$ & $\%$ & p-valor ${ }^{(1)}$ \\
\hline \multicolumn{4}{|c|}{ Você sabe o que é Biossegurança? } \\
\hline Sim & 51 & 94,44 & \multirow{2}{*}{$<0.0001^{* *}$} \\
\hline Não & 3 & 5,56 & \\
\hline \multicolumn{4}{|c|}{ Alguma vez recebeu treinamento em Biossegurança? } \\
\hline Sim & 32 & 59,26 & \multirow{2}{*}{$0.1740^{\text {ns }}$} \\
\hline Não & 22 & 40,74 & \\
\hline \multicolumn{4}{|c|}{ Você conhece as NR's relacionadas às práticas de Biossegurança? } \\
\hline Sim & 26 & 48,15 & \multirow{2}{*}{$0.7850^{\text {ns }}$} \\
\hline Não & 28 & 51,85 & \\
\hline \multicolumn{4}{|c|}{ Você conhece as NR's relacionadas às práticas de Biossegurança? $(n=26)$} \\
\hline NR 32 & 11 & 42,31 & \multirow{6}{*}{$0.0000^{* *}$} \\
\hline NR 06 & 10 & 38,46 & \\
\hline NR 06 e NR 32 & 2 & 7,69 & \\
\hline NR 35 & 1 & 3,85 & \\
\hline NR 05 & 1 & 3,85 & \\
\hline NR 09 e NR 32 & 1 & 3,85 & \\
\hline
\end{tabular}

Fonte: Dados resultantes da pesquisa. ${ }^{(1)}$ Teste Qui-quadrado de Pearson para tendência (p-valor $\left.<0.05\right) .{ }^{* *}$ Valores Altamente significativos; Valores Significativos; nsValores Não Significativos. 
Tabela 2. Distribuição de funcionários participantes da pesquisa, segundo o conhecimento de riscos biológicos. FSCMP, Belém-PA, 2017

\section{Questões}

Durante a sua formação, teve contato com as normas e práticas de Biossegurança?

Sim

Não

Você sabe o que são riscos biológicos?

Sim

Não

Já recebeu/recebe orientações sobre riscos biológicos por escrito?

\begin{tabular}{|c|c|c|c|}
\hline Sim & 21 & 38,89 & \multirow{2}{*}{$0.1020^{\text {ns }}$} \\
\hline Não & 33 & 61,11 & \\
\hline \multicolumn{4}{|l|}{ Se sim, com que frequência? $(n=21)$} \\
\hline Frequentemente & 4 & 19,05 & \multirow{5}{*}{$0.0000^{* *}$} \\
\hline Raramente & 13 & 61,90 & \\
\hline Presença de Sangue ou liquido cefalorraquidiano & 1 & 4,76 & \\
\hline Sempre que aparecem culturas positivas & 1 & 4,76 & \\
\hline Não sabe & 2 & 9,52 & \\
\hline \multicolumn{4}{|l|}{ Foi útil? $(\mathrm{n}=21)$} \\
\hline Sim & 21 & 100,00 & \multirow{2}{*}{$<0.0001^{* *}$} \\
\hline Não & 0 & 0,00 & \\
\hline
\end{tabular}

Fonte: Dados resultantes da pesquisa. ${ }^{(1)}$ Teste Qui-quadrado de Pearson para tendência ( $p$-valor $\left.<0.05\right) .{ }^{*}$ Valores Altamente significativos; * Valores Significativos; ${ }^{\text {ns }}$ Valores Não Significativos.

Tabela 3. Distribuição de funcionários segundo os materiais biológicos a que mais se expõem. FSCMP, Belém-PA, 2017

\begin{tabular}{|c|c|c|}
\hline Quais os materiais biológicos que mais se expõe? & $\mathbf{n}$ & $\%$ \\
\hline SANGUE & 38 & 70,37 \\
\hline SECREÇÕES & 29 & 53,70 \\
\hline URINA & 10 & 18,52 \\
\hline AGULHAS/SERINGAS & 8 & 14,81 \\
\hline FEZES & 5 & 9,26 \\
\hline GOTICULAS & 5 & 9,26 \\
\hline LÍQUIDO CÉFALO RAQUIDIANO & 5 & 9,26 \\
\hline PERFUROCORTANTES & 5 & 9,26 \\
\hline FLUIDOS CORPOREOS & 4 & 7,41 \\
\hline SALIVA & 3 & 5,56 \\
\hline VIRUS E BACTERIAS & 3 & 5,56 \\
\hline MASCARAS DE AEROSOL & 2 & 3,70 \\
\hline DIURESE & 1 & 1,85 \\
\hline DRENOS E SONDAS & 1 & 1,85 \\
\hline EXUDATOS & 1 & 1,85 \\
\hline GASTROSTOMIA & 1 & 1,85 \\
\hline LUVAS & 1 & 1,85 \\
\hline MEDICAÇÕES & 1 & 1,85 \\
\hline PATOGENOS & 1 & 1,85 \\
\hline PRODUTO QUIMICO & 1 & 1,85 \\
\hline VÔMITO & 1 & 1,85 \\
\hline
\end{tabular}

Fonte: Dados resultantes da pesquisa. 
Tabela 4. Distribuição de funcionários participantes da pesquisa, segundo o procedimento de descarte de agulhas e treinamento em Biossegurança. FSCMP, Belém-PA, 2017

\section{Questões}

Você costuma recapar agulhas antes de descartar?

Sim

Não

Não se aplica

Já foi transferido para outro setor dentro do hospital?

$\begin{array}{lrr}\text { Sim } & 28 & 51,85 \\ \text { Não } & 26 & 48,15\end{array}$

Se sim, recebeu treinamento em Biossegurança para o atendimento do novo setor?

$\begin{array}{lccc}\text { Sim } & 6 & 11,11 & <0.0001^{* *} \\ \text { Não se aplica } & 22 & 40,74 & \end{array}$

Fonte: Dados resultantes da pesquisa. ${ }^{(1)}$ Teste Qui-quadrado de Pearson para tendência $(p$-valor $<0.05)$. ** Valores Altamente significativos; Valores Significativos; ${ }^{\text {ns }}$ Valores Não Significativos.

Tabela 5. Distribuição de funcionários participantes da pesquisa segundo o conhecimento dos mapas de risco e sobre os passos de higienização da mão e uso do jaleco. FSCMP, Belém-PA, 2017
Questões
n
$\%$
$p$-valor ${ }^{(1)}$

Você sabe o que são mapas de risco?

Sim

17

31,48

Não

37

68,52

$0.0065^{*}$

Se sim, no seu setor existe algo identificando o risco que o ambiente oferece? $(n=17)$

Sim

Não

Sim

Não

Se sim, com que frequência? $(n=21)$

Antes e após cada procedimento

Antes e após contato com os pacientes

11

6

64,71

35,29

$<0.0001^{* *}$

spital?

54

0

100,00

0,00

$<0.0001^{* *}$

$\begin{aligned} & 75,93 \\ & 1314,07\end{aligned}<0.0001^{* *}$

Você conhece os oito passos de higienização das mãos?

Sim

50

92,59

4

7,41

$<0.0001^{* *}$

Não

Você lava seu jaleco mais de uma vez na semana?

Sim

42

77,78

Não

9

16,67

$<0.0001^{* *}$

Não se aplica

3

5,56

Você tira o jaleco ao sair do hospital?

Sim 51

3

Não se aplica

$\begin{array}{rr}42 & 77,78 \\ 9 & 16,67\end{array}<<0.0001^{* *}$

Existem locais específicos na instituição para o descarte adequado dos materiais perfurocortantes e biológicos?

$\begin{array}{lcrl}\text { Sim } & 54 & 100,00 & <0.0001^{* *} \\ \text { Não } & 0 & 0,00 & \end{array}$

Fonte: Dados resultantes da pesquisa. ${ }^{(1)}$ Teste Qui-quadrado de Pearson para tendência $(p$-valor $<0.05) .{ }^{* *}$ Valores Altamente significativos; * Valores Significativos; Valores Não Significativos. 


\section{Discussão}

Na teoria as normas de Biossegurança são muito bem moldadas no conceito de trabalhar com a prevenção em âmbito hospitalar, sendo essa a melhor alternativa para evitar acidentes, mortes, aquisição de doenças por insalubridade ou até mesmo gasto de dinheiro público com causas trabalhistas.

A presente pesquisa mostra um dado importante que é o fato de que a maioria dos trabalhadores terem declarado que receberam treinamento em Biossegurança, apesar disso menos da metade dos trabalhadores declarou conhecer as NR's relacionadas as práticas de Biossegurança (Tabela 1).

Do total de NR's publicadas pelo Ministério do Trabalho e Emprego cerca de 5 normas estão relacionadas aos serviços de saúde (Tabela 2), dentre elas a NR 06 e a NR 32 tratam sobre tópicos diretamente ligados a saúde do individual trabalhador.

Em pesquisa realizada por Cunha e Mauro $^{7}$ a maioria dos trabalhadores em saúde entrevistados pelos pesquisadores relataram que não receberam treinamento em Biossegurança antes de iniciar as atividades laborais, revelando a necessidade de treinamento com formação específica7 .

A NR 06 trata especificamente do uso de equipamentos de proteção individual, mesmo assim apenas 12 trabalhadores declararam conhecer essa importante norma. Outra norma igualmente importante é a NR 32, considerada um marco para as questões de segurança e saúde no trabalho no setor de saúde ${ }^{8}$. Na presente pesquisa apenas 13 trabalhadores declararam conhecer esta norma.

Um dado importante revelado pela pesquisa é que apenas 2 funcionários declararam conhecer as duas normas, revelando uma necessidade de educação continuada com ênfase nas normas de Biossegurança.

No mês de novembro de 2015 a NR 32 completou 10 anos, porém a maioria das publicações científicas elaboradas sobre a NR 32 são produzidas por profissionais da enfermagem, denotando maior envolvimento dos demais profissionais de saúde, a fim de aumentar o conhecimento sobre esta norma específica ${ }^{9}$.

Os dados exibidos na Tabela 2 ratificam a necessidade da educação continuada para o aumento do conhecimento dos trabalhadores do hospital FSCMP pois faltam orientações para os trabalhadores, inclusive por escrito.

Os dados revelados pela pesquisa estão em concordância com o trabalho publicado por Cunha e Mauro ${ }^{7}$, os quais verificaram que $61 \%$ dos entrevistados não receberam nenhum treinamento em Biossegurança após assumirem seus postos de trabalho ${ }^{7}$.

Os dados constantes na Tabela 3 consolidam a preocupação dos trabalhadores em saúde quanto a um possível contato com o sangue, pois cerca de $70 \%$ dos entrevistados reconheceram que estão mais expostos ao sangue, do que qualquer outro material biológico.

Importante salientar que apenas $9 \%$ dos trabalhadores reconhecem a exposição a gotículas, dado que pode revelar a negligência quanto ao uso de máscaras, outra exigência presente nas NR 06 e NR 32. Os pacientes sem suspeita clínica ou mesmo sem o correto diagnóstico podem oferecer riscos aos trabalhadores em saúde ${ }^{10}$.

Quanto ao comportamento dos funcionários do Hospital FSCMP frente às normas de Biossegurança, a maioria afirmou não encapar novamente as agulhas antes de descartar (Tabela 4), no entanto quase um quinto dos trabalhadores afirmaram incorrer nesta prática desaconselhada pela NR 32.

A ocorrência de acidentes de trabalho com material contaminado com sangue atinge cerca de 385.000 trabalhadores em saúde por ano no mundo ${ }^{10}$. As publicações são unânimes ao constatar que os acidentes afetam majoritariamente as mãos e as perfurações mais comuns são cutâneas ${ }^{11}$ e os casos de soro conversão por acidente com perfuro cortantes com exposição a paciente contaminados pelo vírus do HIV foram de $0,3 \%{ }^{12}$.

Os mapas de risco são uma ferramenta importante para retratar os riscos a que os profissionais de saúde estão expostos, por isso a correta identificação e o completo entendimento desses mapas são fundamentais para se prevenir os acidentes de trabalho ${ }^{13}$.

Nesse cenário a pesquisa revelou, conforme Tabela 5, que a maioria dos funcionários não sabem o que são mapas de risco e dentre os trabalhadores que conhecem os mapas de risco a maioria relatou haver alguma identificação sobre os riscos que o ambiente oferece.

A pesquisa evidenciou que $100 \%$ os trabalhadores higienizam suas mãos em algum momento durante a jornada de trabalho, porém a maioria relata a higienização das mãos antes e depois de cada procedimento, enquanto $24 \%$ dos funcionários apenas faz a higienização antes e depois do contato com os pacientes.

Quando inquiridos sobre o conhecimento dos 8 passos de higienização das mãos, a maioria dos trabalhadores disse conhecer o procedimento, e apenas 7,41\% disseram não conhecer o procedimento. 
Segundo artigo assinado por Mitchell et al. ${ }^{14}$ os jalecos constituem-se como importantes vetores de microrganismos que causam infecções e doenças ${ }^{14}$, além disso a contaminação das mãos dos trabalhadores em saúde também está associada a contaminação dos jalecos ${ }^{15}$. Diante destes fatos os funcionários do hospital FSCMP demonstraram grande preocupação com seus jalecos pois segundo a pesquisa 77,7\% dos trabalhadores declararam lavar os jalecos ao menos uma semana e, o mais importante considerando o jaleco como um vetor de microrganismo, a maioria dos trabalhadores retira o jaleco ao sair do hospital.

\section{Considerações finais}

A pesquisa relatou a percepção dos trabalhadores em saúde do hospital FSCMP servindo, ainda, como um guia para melhorar as ações de Biossegurança, bem como para melhorar a segurança no local de trabalho destes funcionários, sendo verificada a necessidade de fortalecer nos trabalhadores os conceitos relacionados as NR's associadas aos serviços em saúde, como a NR 06 e a NR 32, por meio de implementação de atividades para a educação continuada no que diz respeito ao conhecimento das normas e ações em Biossegurança.

Considera-se importante o investimento em ações educacionais que promovam este conhecimento não somente dentro do ambiente profissional, mas principalmente que se intensifique nos currículos de ensino para que os alunos possam estar previamente preparados para atuar de forma segura nos ambientes de risco.

Dessa forma o conhecimento dos trabalhadores em saúde, bem como a adesão aos parâmetros de Biossegurança foram caracterizados, abrindo o caminho para o treinamento em Biossegurança também em outros setores da FSCMP.

\section{Referências}

1. BRASIL. Ministério da Saúde. Organização Pan-Americana da Saúde. Biossegurança em saúde: prioridades e estratégias de ação. Brasília: Ministério da Saúde; 2010. 242 p.

2. Novack ACM, Karpiuck LB. Acidentes com perfurocortantes em trabalhadores de saúde: revisão de literatura. Rev. Epidemiol. Controle Infecc. 2015;5(2):89-93.

3. Penna PMM, Aquino CF, Castanheira DD, Brandi IV, Cangussu ASR, Sobrinho EM. Biossegurança: uma revisão. Arq Inst Biol (Sao Paulo). 2010;53:555-465.

4. Oliveira JS, Nery AA, Morais RLG, Robazzi MLCC. Acidentes com perfurocortante entre trabalhadores de saúde. Revista APS. 2015;18(1):108-115.

5. Rocha FCS, Meneses R, Cerqueira TCF, Bergamasco MTR, Cacau LAP, Maynard LG. Conhecimento de Biossegurança por profissionais de saúde em unidades hospitalares. Caderno de Graduação - Ciências Biológicas e da Saúde UNIT. 2014;2(1):141-154.

6. Costa MAF, Costa MFC. Educação em Biossegurança: contribuições pedagógicas para a formação profissional em saúde. Ciênc. saúde coletiva. 2010;15(Supl.1):1741-1750.

7. Cunha ACD, Mauro MYC. Educação continuada e a norma regulametnadora 32: utopia ou realidade na enfermagem? Rev Bras Saúde Ocup. 2010;35(122):305-13.

8. Marziale MHP, Galon T, Cassiolato FL, Girão FB. Implantação da Norma Regulamentadora 32 e o controle dos acidentes de trabalho. Acta Paul Enferm. 2012;25(6):859-66.

9. Santos AGD Jr, Santos FRD, Furlan MCR, Araújo JC, Arantes MB, Barbosa TDS. Norma Regulamentadora 32 no Brasil: revisão integrativa da literatura. R. Enferm. Cent. O. Min. 2015:5(1):1528-1534.

10. Marchand G, Duchaine C, Lavoie J, Veillette M, Cloutier Y. Bacteria emitted in ambient air during bronchoscopy - a risk to health care workers? Am J Infect Control. 2016 dez 01;44(12):1634-8. http://dx.doi.org/10.1016/j.ajic.2016.04.241. PMid:27388266.

11. Diaz JC, Johnson LA. Health care worker follow-up compliance after occupational bloodborne pathogens exposure: a brief report. Am J Infect Control. 2016;1(44):1738-40.

12. Nwaiwu CA, Egro FM, Smith S, Harper JD, Spiess AM. Seroconversion rate among health care workers exposed to HIV-contaminated body fluids: the university of Pittsburg 13-year experience. Am J Infect Control. 2017;45(8):896-900.

13. Monteiro GRSS, Silva MES, Oliveira RC. Mapa de risco como instrumento para a identificação de riscos ocupacionais: revisão integrativa da literatura. J. res.: fundam. care. online. 2015;7(3):3076-3092.

14. Mitchell A, Spencer M, Edmiston C Jr. CE. Role of healthcare apparel and other healthcare textiles in the transmission of pathogens: a review of the literature. J Hosp Infect. 2015;90(4):285-92. http://dx.doi.org/10.1016/j.jhin.2015.02.017.

15. Munoz-Price LS, Arheart KL, Mills JP, Cleary T. Association between bacterial contamination of health care worker's hands and contamination of white coats and scrubs. Am J Infect Control. 2012;40(9):e245-8. 


\section{Autor correspondente}

Paulo Eduardo Santos Avila

Rua Bernal do Couto, 1040, Umarizal

CEP 66055-080, Belém, PA, Brasil

E-mail: pauloavila11@yahoo.com.br

\section{Informação sobre os autores}

DMMP é Bacharel em Fisioterapia. NRC é Bacharel em Fisioterapia. MNA é Fisioterapeuta Especialista em Traumato-ortopedia. DCT é Fisioterapeuta Mestre em Fisioterapia. RSBR é Fisioterapeuta Doutor em Ciências do Movimento Humano. PESA é Fisioterapeuta Doutor em Biotecnologia.

\section{Contribuição dos autores}

DMMP executou a parte experimental e escreveu o artigo; NRC executou a parte experimental e escreveu o artigo; MNA realizou a revisão final do artigo; DCT co-orientou a pesquisa; RSBR realizou a revisão final do artigo; PESA orientou a pesquisa e escreveu o artigo. 